\begin{tabular}{cc|c}
\hline Tar. Bil. Der. & Tarım Bilimleri Dergisi & Journal of Agricultural Sciences \\
& $\begin{array}{c}\text { Dergi web sayfası: } \\
\text { www.agri.ankara.edu.tr/dergi }\end{array}$ & Journal homepage: \\
& www.agri.ankara.edu.tr/journal
\end{tabular}

\title{
CBS Kullanılarak Çeltik Tarımı için Arazi Uygunluk Değerlendirmesi: Hayrabolu Deresi Havzası (Trakya Yarımadası) Örneği
}

\author{
Emre ÖZŞAHIN ${ }^{a}$ \\ ${ }^{a}$ Namık Kemal Üniversitesi, Fen-Edebiyat Fakültesi, Coğrafya Bölümü, 59030, Tekirdağ, TÜRKIYE
}

\section{ESER BILGISII}

Araştırma Makalesi

DOI: 10.1501/Tarimbil 0000001388

Sorumlu Yazar: Emre ÖZŞAHIN, E-posta: eozsahin@nku.edu.tr, Tel: +90 (282) 2502696

Geliş Tarihi: 01 Eylül 2014, Düzeltmelerin Gelişi: 17 Şubat 2015, Kabul: 17 Şubat 2015

\section{ÖZET}

Bu çalışmada, Türkiye'nin önemli çeltik ekim alanlarının bulunduğu Trakya Yarımadasında yer alan Hayrabolu Deresi Havzası'nda çeltik tarımı için Coğrafi Bilgi Sistemleri (CBS) destekli arazi uygunluk değerlendirmesinin yapılması amaçlanmıştır. Havza alanı Tekirdağ ilinde çeltik tarımının yapıldığı en önemli sahadır. Bu bakımdan Tekirdağ ilinin Türkiye çeltik üretimine olan katkısını değerlendirmek ve gelecekte yapılacak tarımsal amaçlı planlamalara destek olması açısından çalışmanın önemli olduğu düşünülmektedir. Çalışma amacı kapsamında Dengiz (2013) tarafından kullanılan yöntem içeriğinden yararlanılmıştır. Bu amaçla Ekinci (1990) tarafından bildirilen yöre topraklarının fiziksel ve kimyasal özellikleri kullanılmıştır. Çalışma sonunda Hayrabolu Deresi Havzası'nın \% 74.1 oranla çeltik tarımına uygun arazilerden oluştuğu tespit edilmiştir. Türkiye'deki çeltik ihtiyacındaki artışa bağlı olarak yakın gelecekte havzada yeni sahalarında bu tahılın yetiştirilmesi için kullanılacağı anlaşılmaktadır. Bu bakımdan çeltik tarımına açılacak yeni sahaların bu veya buna benzer farklı çalışmalarla tespit edilip, araştırılması doğal kaynakların kullanımının sürdürülebilir olması bakımından oldukça mühim bir husustur. Sonuç olarak CBS teknikleri kullanılarak gerçekleştirilen bu çalışmanın sonuçları, benzer sahalar için aynı yöntemin rahatlıkla kullanılabileceğini göstermiştir.

Anahtar Kelimeler: Çeltik tarımı; Coğrafi bilgi sistemleri (CBS); Dengiz yöntemi; Arazi uygunluk değerlendirmesi; Hayrabolu deresi havzasi; Tekirdağ

\section{Land Suitability Assessment for Rice Cultivation Using GIS: Hayrabolu Stream Basin (Thrace Peninsula) Case}

\author{
ARTICLE INFO \\ Research Article \\ Corresponding Author: Emre ÖZŞAHIN, E-mail: eozsahin@nku.edu.tr, Tel: +90 (282) 2502696 \\ Received: 01 September 2014, Received in Revised Form: 17 February 2015, Accepted: 17 February 2015
}

\section{ABSTRACT}

This study aims to generate a Geographic Information Systems (GIS) based land suitability assessment for rice cultivation in the Hayrabolu Stream Basin located in the Thrace Peninsula where important rice cultivation areas of Turkey situated. The basin area is most important rice cultivation site in Tekirdağ province. In this regard, the study was considered 
significant attributes for evaluating current contribution of Tekirdağ province to the rice cultivation in Turkey and supporting the future agricultural plans in the region. The method employed by Dengiz (2013) was used in the present study. In addition, the physical and chemical properties of the soils reported by Ekinci (1990) were utilized in the study. It was determined that $74.1 \%$ of the Hayrabolu Stream Basin consisted of typical rice cultivation lands. New sites in the basin may be used for the cultivation of this grain in near future due to increasing rice demand in Turkey. Therefore, determination and characterization of possible new rice sites by means of GIS technologies is quite important for sustainable utilization of natural resources. Consequently results of this study indicated that GIS based techniques could be used for similar sites.

Keywords: Rice cultivation; Geographic information systems (GIS); Dengiz method; Land suitability assessment; Hayrabolu stream basin; Tekirdağ

(C) Ankara Üniversitesi Ziraat Fakültesi

\section{Giriş}

Günümüze kadar yaklaşık 5000 yıldan beri tarımı yapılan çeltik (Özşahin 2008), işlenip pirinç haline getirildiğinde yeryüzündeki çok sayıdaki insanın temel besin maddelerinden birisine dönüşmektedir (Taşlıgil \& Şahin 2011). Bu nedenle tahıllar içerisinde dünya çapında bir öneme sahiptir (Sezer \& Mut 2004). Nitekim Dünya'da çeltik ekimi $156 \times 10^{6}$ ha ve üretimi ise $660 \times 10^{6}$ t'dur (Dengiz 2013). Türkiye'de ise Türkiye İstatistik Kurumu Bitkisel Üretim İstatistikleri Veri Tabanının 2012 y1lı verilerine göre çeltik ekimi 1196639 dekar, üretim ise 880000 t'dur. Bütün bu istatistik veriler gerek dünya, gerekse Türkiye açısından çeltik tarımının önemini göstermektedir.

Günümüzde neredeyse bütün dünya ülkeleri, gerçekleştirdikleri bilimsel çalışmalar ile arazi değerlendirme, arazi kullanım ve tarımsal üretim planlamaları yapmaktadır (Dengiz et al 2009; 2010a; Dengiz \& Sarığlu 2013). Böylece tarımsal anlamda verimlilik özelliklerinin ve kalite indikatörlerinin belirlenmesi sağlanarak sürdürülebilir agroekosistemler oluşturulmaktadır (Dengiz \& Özcan 2006; Dindaroğlu \& Canbolat 2011). Tarımsal ürünler açısından bu tür çalışmalar daha çok arazi uygunluk ve kalite değerlendirmesi şeklinde yapılabildiği gibi (Dengiz \& Baskan 2009), doğal kaynak yönetimi ve çevresel değerlendirme şeklinde de gerçekleştirilebilmektedir (Dengiz et al 2010b). Bu kapsamlı çalışmalar, yaşadığımız bilgi çağında bilgi teknolojisine bağlı olarak Coğrafi
Bilgi Sistemleri (CBS) destekli olarak yapılmaktadır (Dengiz \& Sarığlu 2011).

Perera et al (1993) Sri Lanka'nın güneyinde çeltik tarımı için uygun alanları CBS'ye dayalı olarak araştırmışlardır. Mongkolsawat et al (2002) Kuzeydoğu Tayland'daki Aşağ1 Namphong havzasındaki arazilerin çeltik tarımına uygunluğunu CBS tabanlı arazi değerlendirme modelinde sorgulamışlardır. Usul et al (2006) Amasya ilinin güneybatısında yer alan Gökhöyük Tarım İşletmesinde CBS destekli arazi kalite değerlendirmesi yapmışlardır. Dengiz \& Özcan (2006) Samsun ilindeki Bafra Ovası'nın CBS kullanarak arazi verimlilik özelliklerini belirlemişlerdir. Dengiz et al (2010a) Bafra Ovası'nda çeltik tarımının yapıldığı araziler için CBS tabanlı arazi uygunluk haritalamasını yapmışlardır. Cheng \& Wu (2011) Çin'in Zhejiang ilinde çeltik tarımı ve verimi için CBS destekli uygunluk indeksi belirlemesi ve haritalaması yapmışlardır. Dengiz (2013) İç Anadolu Bölgesi’ndeki Çankırı ilinin Kızılırmak ilçesindeki çalışma alanın çeltik tarımı için CBS tabanlı arazi uygunluk haritalamasını yapmıştır.

$\mathrm{Bu}$ çalışmada CBS kullanılarak Hayrabolu Deresi Havzası'nda çeltik tarımı için arazi uygunluk değerlendirmesinin yapılması amaçlanmıştır. Bu amaçla Dengiz (Dengiz et al 2010a; Dengiz 2013) tarafından kullanılan yöntem içeriğinden yararlanılmıştır.

Çalışma, Tekirdağ ilinde çeltik tarımının yapıldığı en önemli yeri kapsaması, ilin Türkiye 
çeltik üretimine olan katkısını değerlendirmek ve gelecekte yapılacak çalışmalara destek olması açısından büyük önem taşımaktadır. Ayrıca bu çalışma günümüzde, Türkiye'de tarımın karşılaştığı en büyük problem olan verim düşüklüğünün de (Taşlıgil 2010) giderilmesi adına atılacak önemli bir adımı oluşturmaktadır. Son olarak elde edilen bulgular ve sonuçlar, konu hakkında kuramsal çalışmalara ve hipotezlerin geliştirilmesine yardımcı olabileceği gibi, bu konularda çalışacak bilim insanlarına da bir kaynak teşkil edebilecektir.

\section{Materyal ve Yöntem}

\subsection{Inceleme alanının konumu ve genel özellikleri}

İnceleme alanı, Türkiye'nin kuzeybatı kesiminde (Şekil 1), Marmara Bölgesi'nin Ergene Bölümü'nde yer almaktadır. İdari olarak havzanın büyük çoğunluğu Tekirdağ ili sınırları olmak üzere Edirne ve Kırklareli il sınırları dahilinde bulunmaktadır. Havzanın yüzölçümü $1536 \mathrm{~km}^{2}$ olup, Ergene Nehri'nin bir kolu olan Hayrabolu Deresi'nin su bölümü sahasını oluşturmaktadır (Şekil 1).
Trakya Havzası'nda yer alan inceleme alanında, jeolojik olarak Üst Eosen'den günümüze farklı yaş ve türde değişik kayaçlar yayılış göstermektedir. Üst Eosen'den Kuvaterner'e kadar farklı dönemlerde oluşmuş kırıntılılar en geniş sahada bulunur. En genç çökeller ise Kuvaterner'e ait alüvyonlar'dır. Tektonik olarak, Kuzey Anadolu Fayı ailesinin (Şengör 2011) batı uzantısında bulunan Ganos (Saroz-Gaziköy) fayı'nın kuzeyinde konumlanmaktadır (Işı1k 2007).

Havza alanında jeomorfolojik olarak çeşitli yerşekli sistemleri bulunur (Altın et al 1992). Havzanın güney kesiminde inceleme alanının en yüksek kesimleri olan Ganos (Iş̧klar) Dağı yer alır. Havzanın kuzeyinde Ergene Nehri'ne doğru olan kısımlarında alüvyon vadi tabanları şeklinde gelişmiş ovalık sahalar bulunur. Dağ ve ova tabanları arasında aşınım ve birikim yüzeyleri şeklinde plato sahaları yayılış gösterir. Havza alanında yaz mevsiminin sıcak ve kurak, kış mevsiminin ise soğuk ve kar yağışlı bir karakterde olduğu karasal iklim koşulları egemendir (Gürpınar 1994). Bölge genelinde yapılan toprak çalışmalarından elde

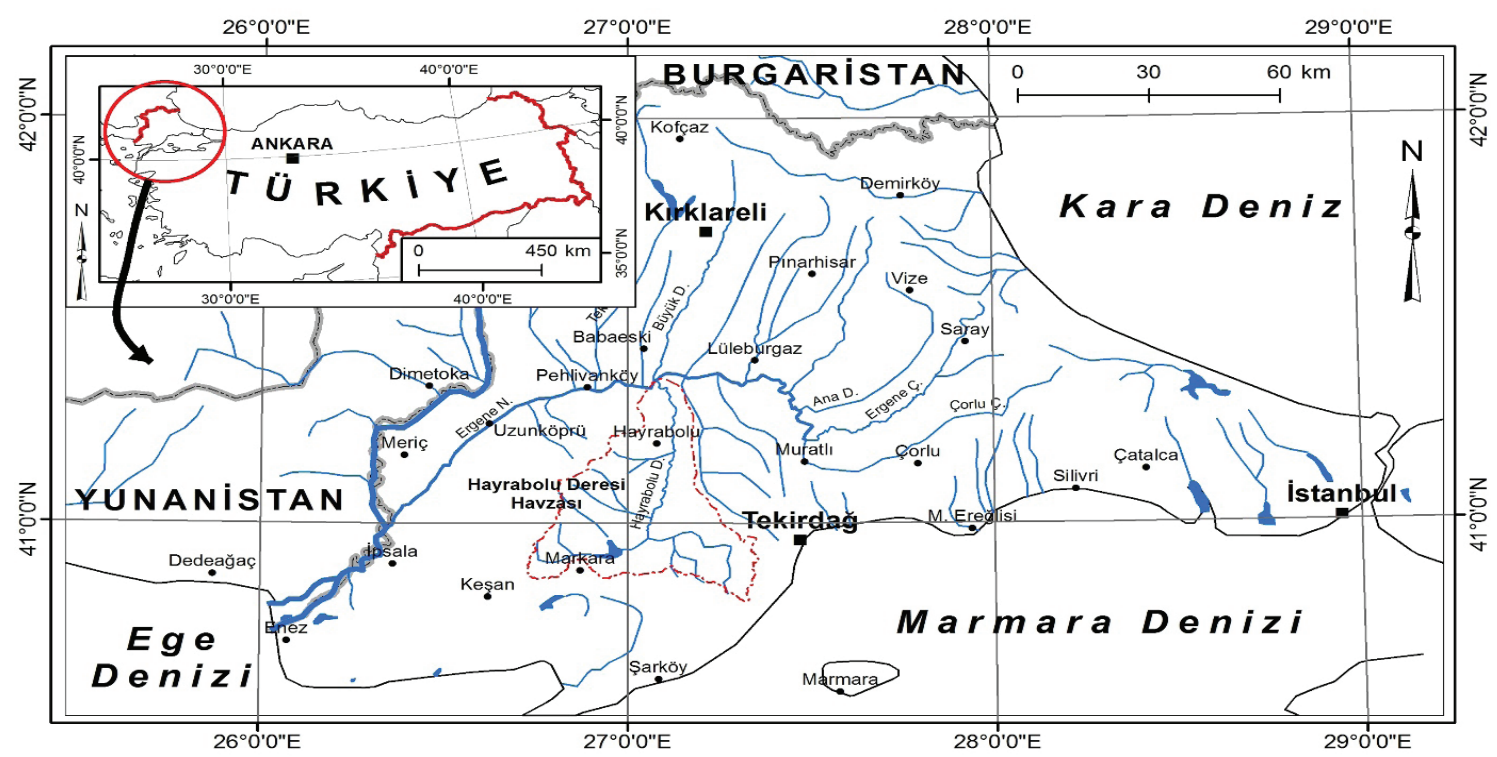

Şekil 1- Havza alanının konumu

Figure 1-Location of basin area 
edilen bilgiler 1şığında havza alanında Toprak Taksonomisine göre Entisol, Alfisol, İnceptisol, Mollisol ve Vertisol olmak üzere 5 toprak ordosu yer almaktadır (Ekinci 1990). Havza alanının doğal bitki örtüsünü ormanlar oluşturur. Saha genelinde kurak ormanlar hakim durumdadır (Dönmez 1990). Buna mukabil havzanın Ganos Dağı'na doğru olan kesimlerinde meşe, gürgen, ihlamur ağaçlarının oluşturduğu nemli ormanlarda yayılış gösterir (Güngördü 1999).

Genel olarak tarımsal amaçlı olarak kullanılan havza alanında en geniş sahada buğday, ayçiçeği, mısır ve çeltik tarımı yapılmaktadır (Adiloglu \& Güler 2010; Orak et al 2012). Ancak çeltik tarımı havza açısından oldukça önemlidir. Zira büyük çoğunluğu Tekirdağ ili sınırları içerisinde kalan havza alanı, 2013 yılında bu ilde çeltik tarımının yapıldığ 1 tek yerdir. Gerçekten de Türkiye İstatistik Kurumu Bitkisel Üretim İstatistikleri Veri Tabanının 2013 yılı verilerine göre (TUIK 2014) çeltik tarımında ülke genelinde ekilen alan (31000 dekar) ve üretim (28899 ton) açısından 7., verim (932 kg $\mathrm{da}^{-1}$ ) açısından da 3. sırada yer alan Tekirdağ ilinde çeltik tarımının yapıldığı tek alan burasıdır (Çizelge 1). Ayrıca bu durum T.C. Orman ve Su İşleri Bakanlığı'ndan elde edilen 1:25000 ölçekli Ulusal Arazi Örtüsü Sinıflandırma sisteminden alınan verilerde de teyit edilmektedir (Şekil 2).

Türkiye İstatistik Kurumu Bitkisel Üretim İstatistikleri Veri Tabanı kayıtlarına (TUIKK 2014) göre havza alanındaki çeltik ekimi ile ilk kayıt 1996 yılında tutulmaya başlanmıştır. Bu dönemde 300 da alanda çeltik tarımı yapılmıştır. Daha sonra bazı yıllarda dalgalanma yaşanmışsa da günümüze kadar çeltik tarımının yaygınlaşarak attığı görülmektedir (Çizelge 2). Çalışmayı daha anlamlı kılmak için geçmiş ve günümüze ait arazi kullanımı verileri karşılaştırılmıştır. Bu karşılaştırma 1999 yılı ve 2013 yıllarına ait çeltik tarlalarının mekânsal dağılışı şeklinde gerçekleştirilmiştir. 1999 yılındaki dağılış 1:100000 ölçekli Tekirdağ İli Arazi Varlığı raporundan (Tekirdağ İli Arazi Varlığı 1999), 2013 y1lındaki dağılış ise 1:25000 ölçekli Ulusal Arazi Örtüsü Sınıflandırma sisteminden alınan veriler çerçevesinde elde edilmiştir. Buna göre 1999 yılında 1500 da alanda lokal olarak yapılan çeltik tarımı, günümüze doğru genişleyerek 2013 yılında 31000 da'a ulaşmıştır (Çizelge 2, Şekil 3). İlgili yıllarda görülen bu artış beşeri faktörlerin yanında doğal faktörlerin de bu sahanın çeltik tarımına müsait olduğunu göstermektedir.

\subsection{Yöntem}

Çeltik tarımı için uygunluk değerlendirmesinin yapılmasının amaçlandığı bu çalışma, bilimsel araştırma yöntemlerine bağlı kalınarak hazırlık; gözlem, ölçme ve istatistik; analiz ve sonuç olmak üzere dört aşamada tamamlanmıştır.

Çalışmanın hazırlık safhasında, öncelikli olarak konu ve alan ile ilgili literatür taranarak gözden geçirilmiştir. Daha sonra temel materyal olarak kullanılacak toprak analizleri ve hâlihazırda bulunan haritalar tedarik edilmiştir. Toprak analizleri için, Ekinci (1990), Adiloglu ve Güler (2010) tarafından yapılan ölçüm sonuçlarından yararlanılmıştır. $\mathrm{Bu}$ yararlanma, havza alanı ve yakın çevresini

Çizelge 1- 2013 yılında havza alanının çeltik tarımı açısından Türkiye ve Tekirdağ ilindeki durumu (TUIKK 2014)

Table 1- The state of the basin area in terms of rice cultivation in Turkey and Tekirdağ province in 2013 (TUiK 2014)

\begin{tabular}{|c|c|c|c|c|c|}
\hline Yer & & $\begin{array}{l}\text { Ekilen alan } \\
\text { (da) }\end{array}$ & $\begin{array}{l}\text { Hasat edilen } \\
\text { alan (da) }\end{array}$ & Üretim (ton) & $\begin{array}{c}\text { Verim } \\
\left(\mathrm{kg} \mathrm{da}^{-1}\right)\end{array}$ \\
\hline Türkiye & & 1105924 & 1105924 & 900000 & 814 \\
\hline Tekirdağ & & 31000 & 31000 & 28899 & 932 \\
\hline \multirow{2}{*}{ Havza alanı } & Hayrabolu & 30000 & 30000 & 28110 & 937 \\
\hline & Malkara & 1000 & 1000 & 789 & 789 \\
\hline
\end{tabular}




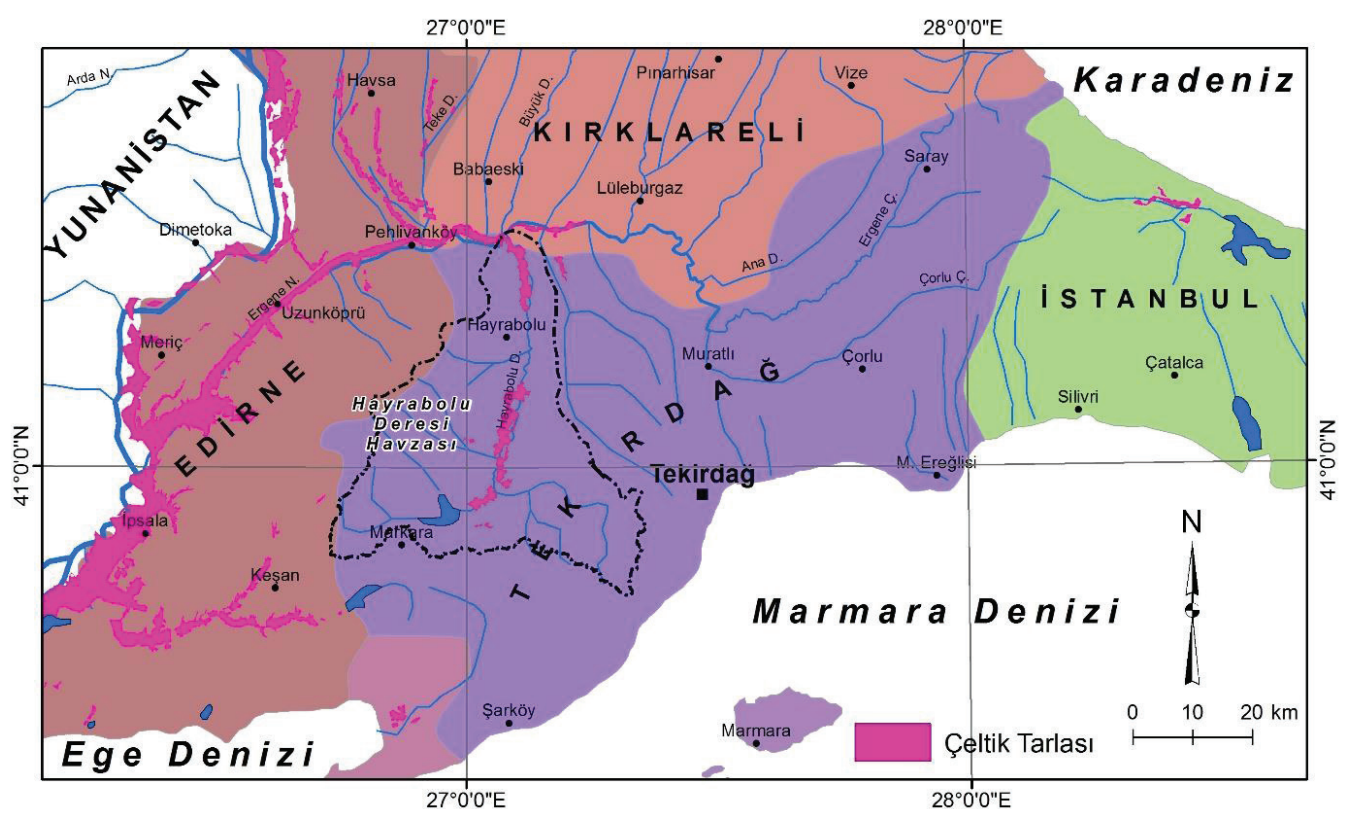

Şekil 2- Havza alanı ve yakın çevresindeki çeltik tarlalarının dağılışı

Figure 2-Distribution of Rice paddies in the basin area and its surroundings

Çizelge 2- Havza alanında çeltik tarımının zamansal değişimi (TUIK 2014)

Table 2- Temporal change of rice cultivation in the basin area (TUIK 2014)

\begin{tabular}{ccccc}
\hline Ylllar & $\begin{array}{c}\text { Ekilen alan } \\
(\text { dekar })\end{array}$ & $\begin{array}{c}\text { Hasat edilen } \\
\text { alan (dekar) }\end{array}$ & $\begin{array}{c}\text { Uretim } \\
(\text { ton })\end{array}$ & $\begin{array}{c}\text { Verim } \\
\left(\mathrm{kg} \mathrm{da}^{-1}\right)\end{array}$ \\
\hline 1996 & 300 & 300 & 150 & 500 \\
1997 & 1200 & 1200 & 535 & 446 \\
1998 & 1480 & 1480 & 808 & 546 \\
1999 & 1500 & 1500 & 794 & 529 \\
2000 & 2050 & 2050 & 2264 & 2033 \\
2001 & 5870 & 5870 & 4206 & 1261 \\
2002 & 6630 & 6630 & 4729 & 1320 \\
2003 & 9220 & 9220 & 6200 & 1316 \\
2004 & 16440 & 16440 & 12255 & 1427 \\
2005 & 17500 & 17500 & 12960 & 1422 \\
2006 & 35177 & 35177 & 25658 & 1491 \\
2007 & 32697 & 32697 & 31809 & 1746 \\
2008 & 35721 & 35721 & 29835 & 1702 \\
2009 & 20500 & 20500 & 17582 & 1716 \\
2010 & 27075 & 27075 & 26255 & 1940 \\
2011 & 25604 & 25604 & 22023 & 1720 \\
2012 & 37700 & 37700 & 30924 & 1606 \\
2013 & 31000 & 31000 & 28899 & 1726 \\
\hline
\end{tabular}




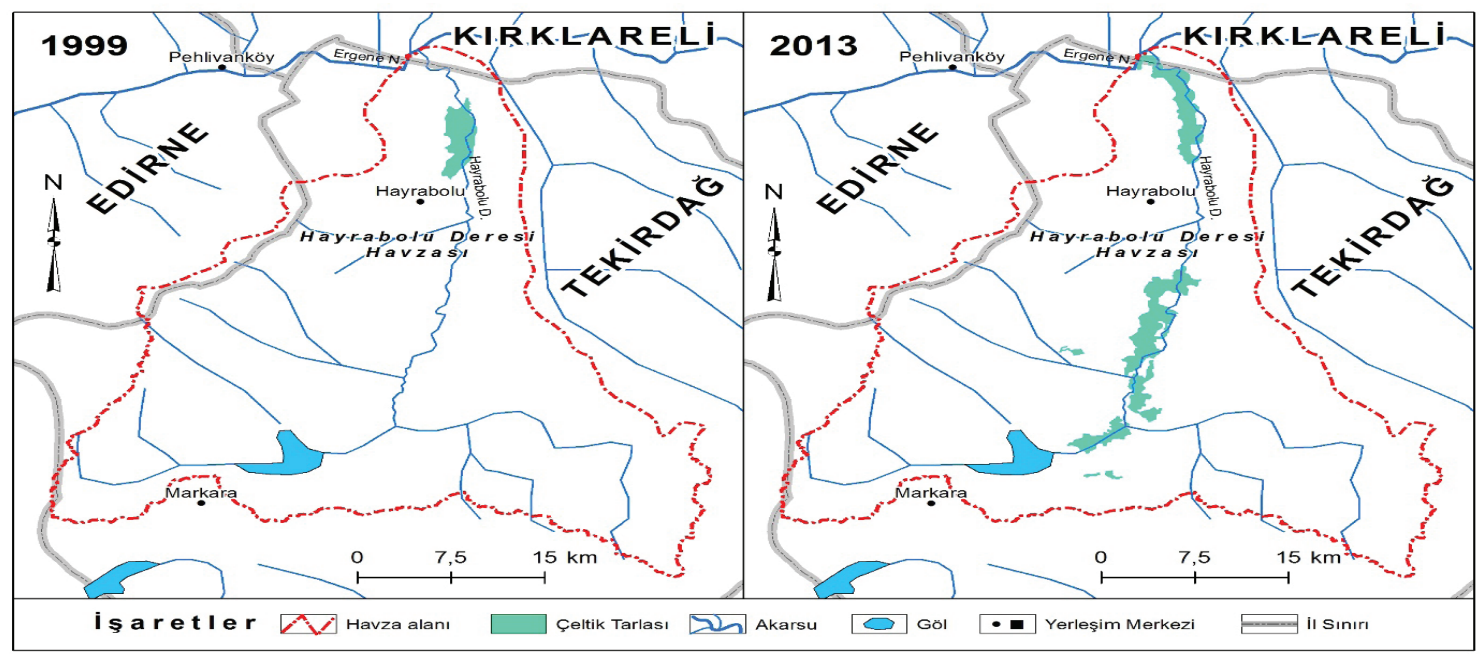

Şekil 3- Havza alanında çeltik tarlalarının 1999 ve 2013 yıllarındaki mekânsal dağılışı

Figure 3- The spatial distribution of paddy field in the basin area in 1999 and 2013 years

karakterize eden 153 toprak örneğinin fiziksel ve kimyasal ölçüm sonuçlarının derlenmesi şeklinde gerçekleştirilmiştir. Analizi yapılan örneklerin drenaj, tekstür, derinlik, tuz, kireç, organik madde, elektriksel iletkenlik (EC), Toprak reaksiyonu (pH), Sodyum (Na), Potasyum (K), Yarayışlı Fosfor $\left(\mathrm{P}_{2} \mathrm{O}_{5}\right)$, Yarayışı 1 Potasyum $\left(\mathrm{K}_{2} \mathrm{O}\right)$, Hacim ağırlığı ve Katyon değişim kapasitesi (KDK) ölçüm sonuçları kullanılmıştır. $\mathrm{Bu}$ sonuçların mekânsal dağılışı toprak parametrelerinin incelenmesinde çok sik kullanılan ve daha iyi olduğu bildirilen (Uygur et al 2010) ters uzaklık ağırlıklandırma (Inverse Distance Weighting-IDW) entarpolasyon yöntemiyle yapılmıştır.

Çalışmada 1:25000 ölçekli topografya paftalarından temel altlık harita olarak yararlanılmıştır. Bunun yanında Japonya Ekonomi, Sanayi ve Ticaret Bakanlığı (METI) Dünya Uzaktan Algılama Veri Analiz Merkezi (ERSDAC) ve Amerika Ulusal Havacılık ve Uzay Dairesi (NASA) tarafından üretilen Sayısal Yükseklik Modeli (GDEM)'nden, Maden Tetkik ve Arama Genel Müdürlüğü (MTA) tarafından yaptırılan 1:500000 ölçekli jeoloji haritasından ve Altın et al (1992) tarafından bildirilen saha hakkındaki jeomorfolojik bilgilerden faydalanılmıştır. Bütün bu verilerin dağılışı ve haritalandırılması, ArcInfo/ ArcMap 10.2 paket programı destekli olarak CBS ortamında gerçekleştirilmiştir.

Çalışmanın gözlem, ölçme ve istatistik aşamasında, havza alanında sistematik bir şekilde arazi çalışmaları yapılmıştır. $\mathrm{Bu}$ esnada, hem literatürden hem de haritalar üzerinden toplanan veriler yerinde kontrol edilmiştir. Yine bu safhada, ilk aşamadaki toprak analiz sonuçları Microsoft Excel 2013 programında düzenlenmiş ve CBS tabanına Microsoft Access 2013 yazılımı kullanılarak aktarılmıştır.

Çalışmanın analiz kısmı, 10x10 m çözünürlüğünde üretilen grid haritalarla üç aşamada tamamlanmıştır. Bu safhada Dengiz (Dengiz et al 2010a; Dengiz 2013) tarafından çeltik tarımı için kullanılan metodolojiden istifade edilmiştir. Analiz kısmının ilk aşamasında besin elementi yarayışlılık indeksi, ikinci aşamada toprak kalitesi indeksi ve üçüncü aşamada ise arazi uygunluk indeksi tespit edilmiştir (Şekil 4, Çizelge 3).

Arazi kalite parametreleri çeltik tarımı için önem derecesine göre atanmıştır. Bu bakımdan Dengiz (Dengiz et al 2010a; Dengiz 2013) tarafindan bildirilen arazi uygunluk parametreleri ve indeks 
değerleri kullanılmıştır. İndeks değerlerinden yararlanılarak tanımlanan faktör haritaları oluşturulmuştur.

Elde edilen faktör haritaları kullanılarak önce besin elementi yarayışlılık indeksi Eşitlik 1'e göre analiz edilmiştir.

$\mathrm{NAI}=\mathrm{NA} \times \mathrm{K} \times \mathrm{P}_{2} \mathrm{O}_{5} \times \mathrm{K}_{2} \mathrm{O}$

Burada; NAI, besin elementi yarayışlılık indeksi; $\mathrm{Na}$, Sodyum; K, Potasyum; $\mathrm{P}_{2} \mathrm{O}_{5}$ (Yarayışlı fosfor) ve $\mathrm{K}_{2} \mathrm{O}$ (Yarayışlı potasyum)'dur.

İkinci olarak ise toprak kalite indeksi Eşitlik 2'ye göre analiz edilmiştir.

$\mathrm{SQI}=\mathrm{R} \times \mathrm{T} \times \mathrm{D} \times \mathrm{F} \times \mathrm{S} \times \mathrm{K} \times \mathrm{OM} \times \mathrm{EC} \times \mathrm{H} \times \mathrm{V} \times \mathrm{C}$

Burada; SQI, toprak kalite indeksi; R, drenaj; T, tekstür; D, derinlik; F, topografya; S, tuz; K, kireç; OM, organik madde; EC, elektriksel iletkenlik; $\mathrm{H}$, toprak reaksiyonu; $\mathrm{V}$, hacim ağırlı̆̆ı; $\mathrm{C}$, katyon değişim kapasitesidir.
Her iki aşamada uygulanan eşitlik içerikleri doğrultusunda oluşturulan faktör haritaları ise Eşitlik 3 kapsamında birleştirilmiştir.

$\mathrm{SI}=\mathrm{NAI} \times \mathrm{SQI}$

Burada; SI, uygunluk indeksi; NAI, besin elementi yarayışlılık indeksi ve SQI, toprak kalite indeksi'dir.

Nihai aşamada elde edilen uygunluk indeksi haritas1 Dengiz (Dengiz et al 2010a; Dengiz 2013) tarafından yapılan ayrım göz önünde bulundurularak 4 sınıf altında sıralanmıştır (Çizelge 4).

Çalışmanın sonuç aşamasında ise hem literatür taraması hem de arazi çalışmalarından elde edilen veriler, güncel çalışmalar 1şı̆̆ında değerlendirilmiştir. Elde edilen bulgular tartışılarak güncel bazı problemlerle ilişkilendirilmiş ve çeşitli öneriler geliştirilmiştir.

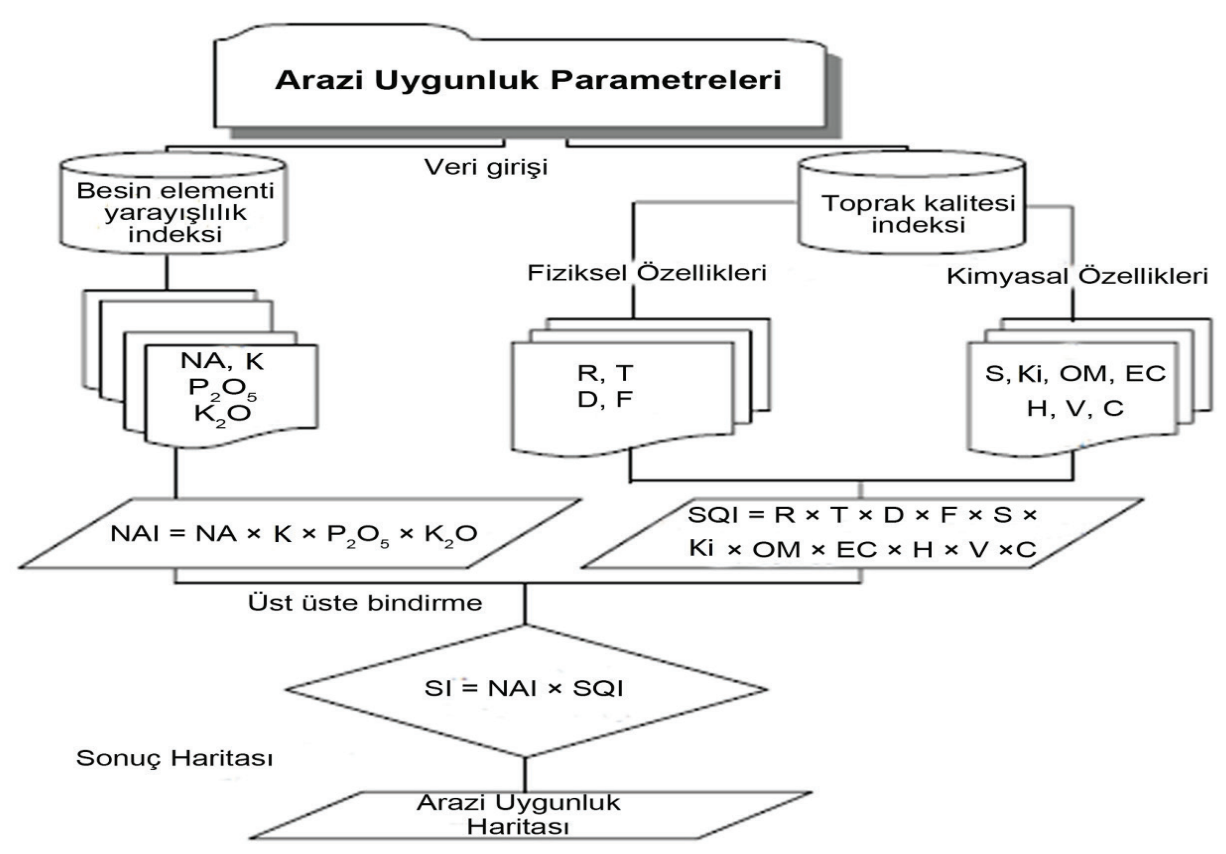

Şekil 4- Havza alanında çeltik tarımı için arazi uygunluk değerlendirmesindeki CBS uygulamalarının sistematik şeması

Figure 4- Schematic chart of GIS application to land suitability assessment for rice cultivation in the basin area 


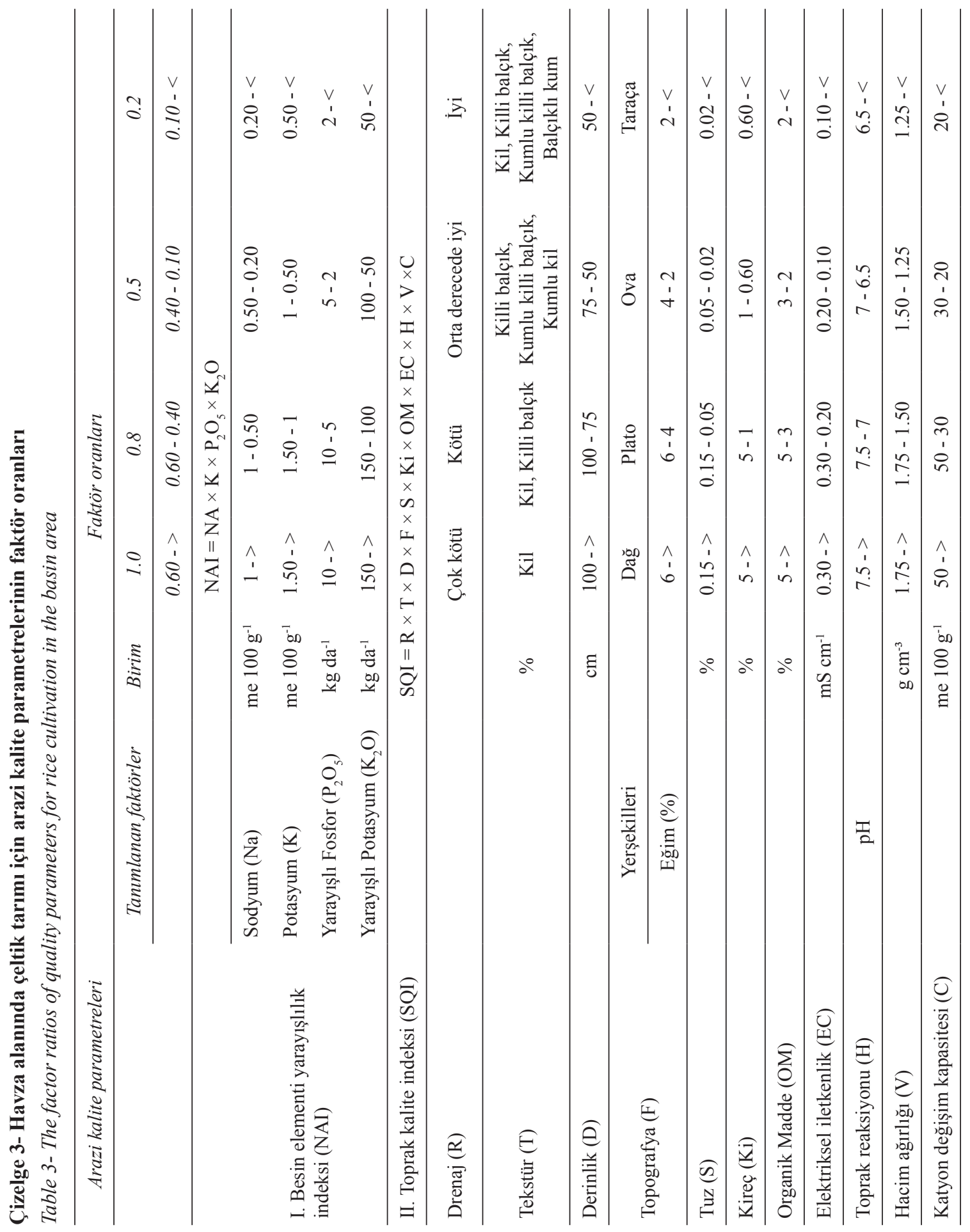


Çizelge 4- Çeltik tarımı için arazi uygunluk değerlendirmesi

Table 4- Land suitability evaluation for rice cultivation

\begin{tabular}{lcc}
\hline Tanımlama & Uygunluk sinıfi & İndeks dĕ̌eri \\
\hline Çok uygun & $\mathrm{S} 1$ & $1.00-0.250$ \\
Orta derecede uygun & $\mathrm{S} 2$ & $0.250-0.100$ \\
Uygun & $\mathrm{S} 3$ & $0.100-0.025$ \\
Uygunsuz & $\mathrm{N}$ & $0.025-<$ \\
\hline
\end{tabular}

\section{Bulgular ve Tartışma}

Dünya nüfusunun beslenmesindeki üç önemli tahıldan biri olan (Zaman 2001; Doğanay 2007) çeltik, işlendiğinde dünya nüfusunun yarısından fazlasının temel gıdasını oluşturmaktadır (Bulut 2006; Özşahin 2008). Bu nedenle Türkiye tarımında çok önemli bir yer teşkil etmektedir (Taşlıgil \& Şahin 2011). Bilhassa gerek Dünya, gerekse Türkiye ölçeğinde çeltik tarımı kapsamında yapılan çalışmalar bu bakımdan oldukça önemli ve zaruri bir durum kazanmaktadır.

Tekirdağ ilinde çeltik tarımının yapıldığı tek saha olan Hayrabolu Deresi Havzası'nda çeltik tarımı için arazi uygunluk değerlendirilmesinin yapıldığ bu çalışmada kullanılan toprak analizlerindeki tüm örneklerin, besin elementi yarayışl1lık ve toprak kalite indeksleri değerlendirilmiştir.

Çalışmanın analiz kısmının ikinci safhası olan toprak kalite indeksi'nin tespit edilmesinde ise drenaj, tekstür, derinlik, topografya, tuz, kireç, organik madde, elektriksel iletkenlik, toprak reaksiyonu, hacim ağırlığı ve katyon değişim kapasitesi gibi parametreler değerlendirilmiştir. Bu bağlamda çeltik tarımı için en müsait alanlar; drenajın kötü (Meral \& Temizel 2006), toprak tekstürünün killi yapıda (Er \& Geçit 1988), toprak derinliğinin fazla (Göney 1980; Özgöz et al 2012), yerşekillerinin düz ya da düze yakın (Taşlıgil \& Şahin 2011), eğimin az (Sürek 2002), kireç oranının düşük (Doğanay 2007), organik madde bakımından zengin (Sürek 2002), elektriksel iletkenliğin düşük (Sürek 2002), toprak reaksiyonunun 8.5 'ten düşük (Sürek 2002), hacim ağırlığı ve katyon değişim kapasitesinin (kil oranıla doğru orantılıdır) ise yüksek (Ekinci 1990) olduğu yerlerdir.
Bu çalışma kapsamında formül içerikleri dâhilinde gerçekleştirilen analizler sonucunda, Hayrabolu Deresi Havzası'nın çeltik tarımı için uygun olduğu anlaşılmıştır. Zira havza alanın \% 26.1'i uygun, \% 24.8'inin orta derecede uygun ve \% 23.8'inin de çok uygun sahalardan oluşmaktadır (Çizelge 5). Havza alanında çeltik tarımı için en uygun alanlar başta Hayrabolu Deresi olmak üzeri bu akarsuya ait kolların oluşturduğu alüvyon vadi tabanlarıdır (Şekil 5). Çeltik tarımı için uygunsuz sahaların oranı ise \% 25.9'dur (Çizelge 5). Havzanın güneyinde Ganos Dağı'na doğru olan kesimleri ile Hayrabolu şehrinin batısındaki plato sahaları da çeltik tarımı için uygunsuz alanlar kategorisindedir (Şekil 5). Diğer arazi uygunluk sınıfları ise bu gruplar arasında dağılış gösterir (Şekil 5).

Çizelge 5- Havza alanında çeltik tarımı için arazi uygunluk sınıflarının dağılışı

Table 5-Distribution of land suitability classes for rice cultivation in the basin area

\begin{tabular}{lcc}
\hline Uygunluk sinıfi & Alan $\left(\mathrm{km}^{2}\right)$ & Oran $(\%)$ \\
\hline S1: Çok uygun & 365.2 & 23.8 \\
S2: Orta derecede uygun & 372.2 & 24.2 \\
S3: Uygun & 401.2 & 26.1 \\
N: Uygunsuz & 397.4 & 25.9 \\
\hline Toplam & 1536.0 & 100.0 \\
\hline
\end{tabular}

Çalışma sonucunda tespit edilen arazi uygunluk sınıflarının oranları havzanın çeltik tarımına müsait olduğunu desteklemektedir. Zira benzer bulgulara literatürde de erişilmiştir. Perera et al (1993) Sri Lanka'nın güneyi için yaptıkları çalışmada bu sahanın \% 72'sinin çeltik tarımına çok uygun veya uygun olduğunu tespit etmişlerdir. Mongkolsawat et al (2002) Kuzeydoğu Tayland'daki Aşağı Namphong havzasının \% 17.7'sinin çeltik tarımı için müsait olmadığını belirlemişlerdir. Dengiz et al (2010a) Bafra Ovası'nın bir kısmını kapsayan çalışmalarında inceledikleri alanın \% 79'unun çeltik tarımına çok uygun ve uygun arazilerden oluştuğu bulgusuna erişmişlerdir. Cheng \& Wu (2011) Çin'in Zhejiang ilinin çeltik tarımına çok uygun olduğunu ortaya koymuşlardır. Dengiz (2013) İç Anadolu Bölgesi'ndeki Çankırı ilinin Kızılırmak ilçesindeki çalışma alanın çeltik tarımı açısından çok uygun ve uygun arazilerden oluştuğu sonucuna ulaşmıştır. 


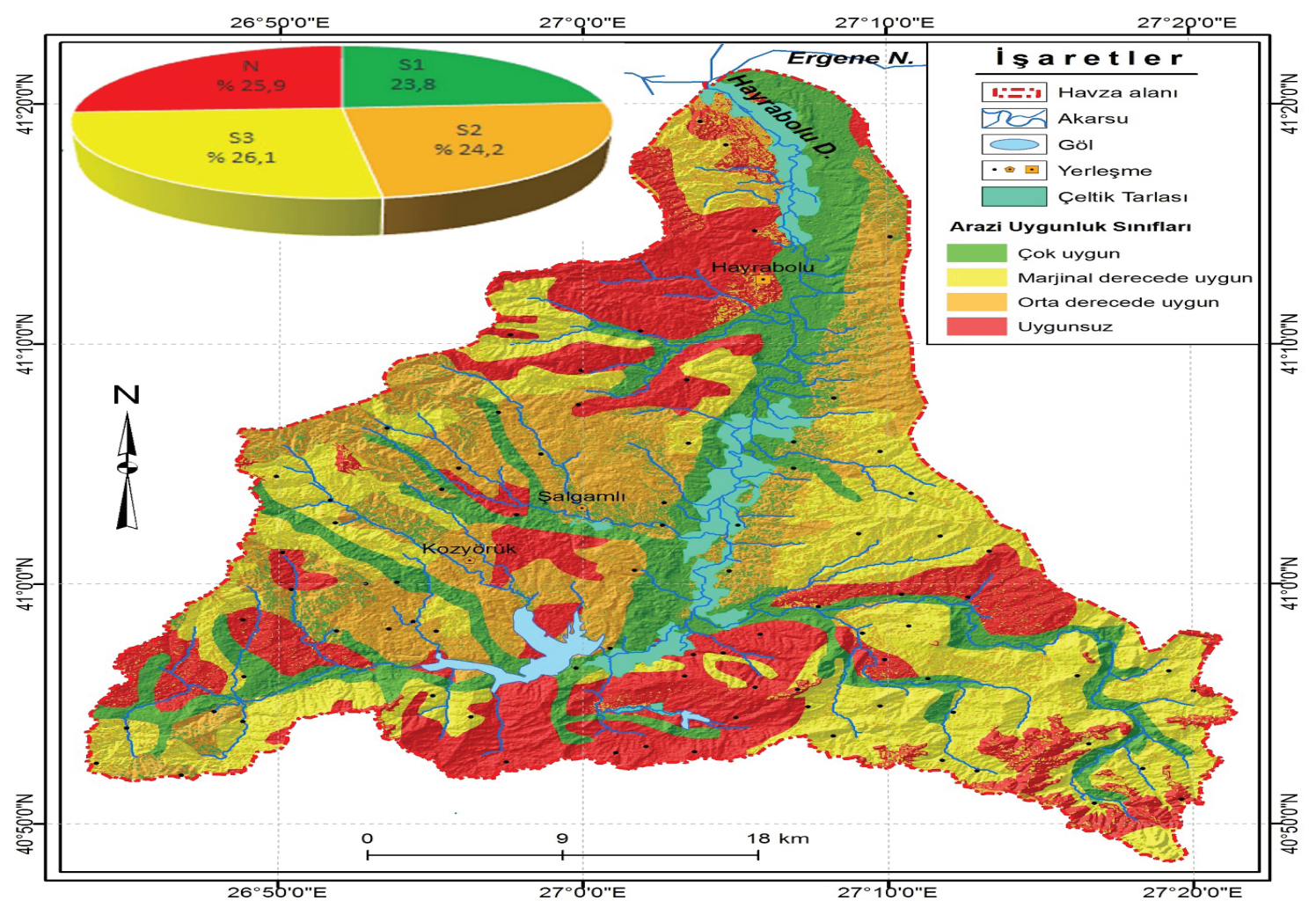

Şekil 5- Havza alanının çeltik tarımı için arazi uygunluk değerlendirmesi haritası

Figure 5- Land suitability assessment map for rice cultivation in the basin area

Hayrabolu Deresi Havzası'ndaki çeltik tarımına uygun alanların dağılış sonuçları ayrıca, hâlihazırda çeltik tarımının yapıldı $\breve{g} 1$ sahalarla paralellik göstermektedir (Şekil 5). Bu uyumluluk çalışma bulgularının da doğru olduğuna işaret etmektedir.

Bununla birlikte CBS tabanlı arazi uygunluk çalışmaların planlama ve yönetim açısından olduğu kadar, doğal kaynakların korunmasında da önemli olduğu anlaşılmıştır. Dengiz \& Özcan (2006) benzer çalışmaların doğal kaynakların, özellikle toprakların, karakteristiklerine uygun sürdürülebilir bir şekilde üretkenliklerinin devamlılığı sağlamaya yardımcı olduğunu belirtmişlerdir. Dengiz et al (2007) bu tür çalışmaların birçok veriyi doğru ve hızlı bir şekilde analiz edilmesinde planlamacılara önemli kolaylıklar sağladığını bildirmişlerdir. Dengiz et al (2009) CBS destekli tarımsal kullanıma uygunluk çalışmalarının, hem kullanıcılara hem de karar vericilere kararların alınmasında çabukluk ve esneklik kazandırdığının altını çizmişlerdir.

\section{Sonuç}

Bu çalışma sonunda Tekirdağ ilinde tek çeltik tarımın yapıldığı yer olan Hayrabolu Deresi Havzası'nın $\% 74.1$ oranla çeltik tarımına uygun arazilerden oluştuğu tespit edilmiştir. Türkiye'deki çeltik yetiştirilmesindeki artış eğilimine bakılarak yakın gelecekte havza alanında yeni sahalarında bu tahılın yetiştirilmesi için kullanılacağ 1 anlaşılmaktadır. $\mathrm{Bu}$ bakımdan çeltik tarımına açılacak yeni sahaların bu veya buna benzer farklı çalışmalarla tespit edilip, araştırılması doğal kaynakların kullanımının 
sürdürülebilir olması bakımından oldukça mühim bir husustur.

Son olarak CBS teknikleri kullanılarak gerçekleştirilen bu çalışmanın sonuçları, benzer sahalar için aynı yöntemin rahatlıkla kullanılabileceğini göstermiştir.

\section{Kaynaklar}

Adiloglu A \& Güler M (2010). Hayrabolu Yöresi Tarım Topraklarının Verimlilik Durumu. Hayrabolu Değerleri Sempozyumu 13 Ekim 2010, s. 41-46, Tekirdağ

Altın B N, Eldeniz Ş \& Kayacılar C (1992). Hayrabolu dolayının jeomorfolojik ve neotektonik gelişimiErgene Nehri Havzası Güneyi, Trakya. I. $\ddot{U}$. Deniz Bilimleri ve Coğrafya Enstitüsü Bülten 9(9): 299-307

Bulut İ (2006). Genel Tarım Bilgileri ve Tarımın Coğrafi Esasları (Ziraat Coğrafyası). Gündüz Eğitim ve Yayınc1lık, Ankara

Cheng Q \& Wu X (2011). Mapping paddy rice yield in Zhejiang Province using MODIS spectral index. Turkish Journal of Agriculture and Forestry 35: 579589

Dengiz O \& Özcan H (2006). Samsun-Bafra Ovas1 topraklarının CBS yardımıyla verimlilik indekslerinin (PI) belirlenmesi. Selçuk Üniversitesi Ziraat Fakültesi Dergisi 20(38): 136-142

Dengiz O \& Baskan O (2009). Land quality assessment and sustainable land use in Salt Lake (Tuz Gölü) specially protected area. Environmental Monitoring and Assessment 148: 233-243

Dengiz O, Özdemir N, Öztürk E \& Yakupoğlu T (2009). Doğu Karadeniz Bölgesi findık arazilerinin tarımsal kullanıma uyguluk sinıflarının belirlemesi, pilot çalışma; Ünye-Tekkiraz beldesi. Anadolu Tarım Bilimleri Dergisi 24(3): 174-183

Dengiz O, Sezer İ, Özdemir N, Göl C, Yakupoğlu T, Öztürk E, Sirat A \& Şahin M (2010a). Application of GIS model in physical land evaluation suitability for rice cultivation. Anadolu Tarım Bilimleri Dergisi 25(S-3): 184-191

Dengiz O, Ozcan H, Koksal S E, Baskan O \& Kosker Y (2010b). Sustainable natural resource management and environmental assessment in the Salt Lake (Tuz Golu) Specially Protected Area. Environmental Monitoring and Assessment 161: 327-342
Dengiz O \& Sarığlu F E (2011). Samsun ili bazı arazi özellikleri ve arazi kullanım durumlarının topografik özellikleri ile birlikte CBS analizleri. Ege Üniversitesi Ziraat Fakültesi Dergisi 48(1): 55-60

Dengiz O \& Sarığlu F E (2013). Arazi değerlendirme çalışmalarında parametrik bir yaklaşım olan doğrusal kombinasyon tekniği. Tarım Bilimleri DergisiJournal of Agricultural Sciences 19: 101-112

Dengiz O (2013). Land suitability assessment for rice cultivation based on GIS modeling. Turkish Journal of Agriculture and Forestry 37: 326-334

Dindaroğlu T \& Canbolat M Y (2011). Kuzgun baraj gölü su üretim havzasının toprak kalitesi bakımından değerlendirilmesi. Atatürk Üniversitesi Ziraat Fakültesi Dergisi 42(2): 145-151

Doğanay H (2007). Ekonomik Coğrafya 3 (Ziraat Coğrafyas1). Aktif Yayınları, Erzurum

Dönmez Y (1990). Trakya'nın Bitki Coğrafyası. Genişletilmiş İkinci Bask1, İstanbul Üniversitesi Yayınları No: 3601, Coğrafya Enstitüsü Yayınları No: 51 , İstanbul

Ekinci H (1990). Türkiye Genel Toprak Haritasının Toprak Taksonomisine Göre Düzenlenebilme Olanaklarının Tekirdağ Bölgesi Örneğinde Araştırılması. Doktora tezi, Çukurova Üniversitesi Fen Bilimleri Enstitüsü Toprak Anabilim Dalı (Basılmamış), Adana

Er C \& Geçit H H (1988). Çeltik. Garanti Bankası Tarım Bilgileri Dizisi 6, Ankara

Göney S (1980). Sicak Bölgelerde Ziraat (Ziraat Coğrafyas1). Cilt: IV, Coğrafya Enstitüsü Yayınları No: 116, İstanbul Üniversitesi Edebiyat Fakültesi Yayınları No: 2732, İstanbul

Güngördü M (1999). Marmara Bölgesinin Bitki Coğrafyası. İstanbul Üniversitesi Edebiyat Fakültesi Yayınları No: 3416, İstanbul

Gürpınar E (1994). Bir Çevresel Analiz Örneği Trakya. Der Yayınları, İstanbul

Horuz A, Korkmaz A \& Karaman M R (2013). Çeltik topraklarının silisyumlu gübrelemeye tepkisi. Tarım Bilimleri Dergisi-Journal of Agricultural Sciences 19: $268-280$

Işık Ü (2007). Nusratlı-Yağc1-Tekirdağ arasındaki bölgenin hidrojeolojisi. Yüksek Lisans Tezi, İstanbul Teknik Üniversitesi Fen Bilimleri Enstitüsü Jeoloji Mühendisliği Anabilim Dalı Uygulamalı Jeoloji Programı (Basılmamış), İstanbul 
Meral R \& Temizel K E (2006). Çeltik Tarımında Sulama Uygulamaları ve Etkin Su Kullanımı. KSÜ Fen ve Mühendislik Dergisi 9(2): 104-109

Mongkolsawat C, Thirangoon $\mathrm{P} \&$ Kuptawutinan $\mathrm{P}$ (2002). A physical evaluation of land suitability for rice: A methodological study using GIS. Computer Centre, Khon Kaen University, Thailand

Orak A, Sağlam N \& Üngör M G (2012). Hayrabolu Köylerinde Çiftçilerin Sorunlarına Yönelik Yapılan Anket Çalışması. Hayrabolu Tarla Bitkileri Üretim Sorunları ve Çözüm Önerileri Paneli. Namık Kemal Üniversitesi Ziraat Fakültesi Tarla Bitkileri Bölümü, Tekirdağ

Özgöz E, Günal H, Önen H, Bayram M \& Acir N (2012). Effect of management on spatial and temporal distribution of soil physical properties. Tartm Bilimleri Dergisi-Journal of Agricultural Sciences 18: 77-91

Özşahin E (2008). Gönen Ovasında Pirinç Tarımı. Fırat Üniversitesi Sosyal Bilimler Dergisi 18(2): 49-70

Perera L K, Kajiwara K \& Tateishi R (1993). Land suitability assessment by GIS for paddy cultivation in Sri Lanka. With a concern on environmental protection. In: Geoscience and Remote Sensing Symposium, IGARSS. Better Understanding of Earth Environment 4: 2076-2078

Sezer İ \& Mut Z (2004). Samsun ilinde çeltik tarımının durumu ve üretimi arttırmak için öneriler. GOÜ. Ziraat Fakültesi Dergisi 21(1): 57-66
Sürek H (2002). Pirinç Tarımı. Hasad Yayıncılık, İstanbul

Şengör A M C (2011). İstanbul Boğazı Niçin Boğaziçi’nde Açılmıştır? Fiziki Coğrafya Araştırmaları; Sistematik ve Bölgesel, Türk Coğrafya Kurumu Yayınları No: 5, s. 57-102, İstanbul

Taşlıgil N (2010).Türkiye Ziraatının Problemleri. Çantay Kitabevi, İstanbul

Taşligil N \& Şahin G (2011). Türkiye'de çeltik (Oryza sativa L.) yetiştiriciliği ve coğrafi dağılımı. Adıyaman Üniversitesi Sosyal Bilimler Enstitüsü Dergisi 4(6): 182-203

Tekirdağ İli Arazi Varlığı (1999). Köy Hizmetleri Genel Müdürlüğü Yayınları. İl Rapor No: 59, Ankara

TUİK (2014). Türkiye İstatistik Kurumu Bitkisel Üretim İstatistikleri Veri Taban1. http://tuikapp.tuik.gov.tr/ bitkiselapp/bitkisel.zul. (Erişim tarihi: 29.03.2014)

Usul M, Dilsiz A \& Tuğaç M G (2006). Gökhöyük tarım işletmesi topraklarının kalite durumlarının değerlendirilmesi. Atatürk Üniversitesi Ziraat Fakültesi Dergisi 37(1): 21-27

Uygur V, Irvem A, Karanlik S \& Akis R (2010). Mapping of total nitrogen, available phosphorous and potassium in Amik Plain, Turkey. Environmental Earth Sciences 59: 1129-1138

Zaman M (2001). Çarşamba Ovası'nda çeltik tarımı. Doğu Coğrafya Dergisi 7(5): 447-479 